\title{
Assessing the ability of infiltration-based WSUD systems to manage channel-forming flow regimes in greenfield catchment developments: A catchment scale investigation
}

\author{
W.H.C. Subhashini ${ }^{a}$, G.A. Hewa ${ }^{\text {ab }}$ and D. Pezzaniti ${ }^{\text {b }}$ \\ ${ }^{a}$ School of Natural and Built Environments, University of South Australia, Mawson Lakes, SA 5095, \\ Australia \\ ${ }^{b}$ Centre for Water Management and Reuse (CWMR), University of South Australia, Mawson Lakes, SA 5095, \\ Australia \\ E-mail: chathurika_subhashini.wella_hewage@mymail.unisa.edu.au
}

\begin{abstract}
Catchment urbanisation is an inevitable and growing form of land-use change. These land-use changes have profound impact on catchment hydrology by altering the quantity and quality domains of flow characteristics in stream channels resulting in increased flood hazards, degraded aquatic ecosystem health and changed channel geometry. The concept of stormwater source control emerged from the need for managing stormwater in urbanised catchments with the aim of alleviating the detrimental impacts of catchment urbanisation on flow regimes, associated stream geometry and ecosystems health. These source control techniques are called Water Sensitive Urban Design (WSUD) in Australia and are increasingly being endorsed and adopted for managing stormwater in urbanising catchments. Consequently, the hydrologic response in urban and peri-urban catchments will be decided or influenced by the WSUD systems in those catchments in the future.
\end{abstract}

This paper focuses on assessing the ability of infiltration-based WSUD systems in maintaining channelforming flow regimes in greenfield catchment developments. The performance evaluation methodology is demonstrated by constructing hydrologic models for natural, urban, and managed (with WSUD) conditions for a selected case study catchment. The US Environmental Protection Agency Storm Water Management Model (SWMM) is used as the modelling tool. WSUD systems were designed based on the use of the flow duration control approach based on continuous simulation of flows. Two urbanisation levels were investigated: $30 \%$ and $70 \%$ of directly connected impervious area (DCIA) of the catchment in the study.

The system performance was assessed using selected flow indices. The results of the study depicts that urbanisation dramatically change the natural flow regime. Under urbanised conditions of the catchment, magnitude of peak flow was notably increased while low flow was reduced. The increased frequency and duration of channel-forming flow was also evident under catchment urbanisation. The implementation of infiltration-based systems helps to reduce the impact of urbanisation by bringing flow values close to their natural conditions value. The infiltration-based WSUD systems adopted in this study can manage the channel-forming flow magnitude, frequency and duration close to their predevelopment levels. The adopted WSUD systems effectively reduce increased runoff volumes under urban conditions close to natural volumes. The percentage of time that flows exceeded $\mathrm{Q}_{1.67}$ increased from the natural value of $0.71 \%$ to $1.9 \%$ at $30 \%$ DCIA scenario and employing bioretention systems in the developed catchment effectively reduced flow frequencies of $\mathrm{Q}_{1.67}$ back to $0.63 \%$. The magnitude of $\mathrm{Q}_{1.67}$ increased by $586 \%$ from the natural catchment value at $30 \%$ DCIA and stormwater management using bioretention systems reduced the statistic down to $13 \%$ of natural value. The duration of $\mathrm{Q}_{1.67}$ flow was increased by $170 \%$ from its natural value at $30 \%$ DCIA scenario and with the implementation of WSUD systems, $\mathrm{D}_{\mathrm{Q} 1.67}$ reduced up to $11 \%$ below its natural value. Similar results were obtained for $70 \%$ DCIA scenario. These improvements in streamflow regime would reduce the impact of urbanisation on channel geometry and ecological health.

Keywords: Catchment modelling, Water Sensitive Urban Design (WSUD), Source Control, Storm Water Management Model (SWMM) 


\section{INTRODUCTION}

Catchment urbanisation is a universal and rapidly growing form of land-use change (Paul and Meyer, 2001). These land-use changes, which transform natural catchments into urban landscape, induce a host of environmental impacts. Urbanisation alters the catchment's hydrological processes, which result in changes in streamflow regimes. Increased catchment imperviousness and the conventional stormwater drainage systems established in urban areas amplify the runoff volume and peak flows, beyond those of undeveloped catchments, thus altering the natural flow regime. Dramatically modifying the natural flow regime affects both fluvial morphology (Booth, 1991; Bledsoe and Watson, 2001) and aquatic and riparian ecosystems (Poff et al., 1997; Konrad and Booth, 2005). These modifications in runoff characteristics and in-stream processes caused by changed land-use are termed hydromodification.

Stormwater source control is increasingly being used to minimise the adverse hydrologic impacts of catchment urbanisation. These stormwater source control techniques are called Water Sensitive Urban Design (WSUD) in Australia. The aim of stormwater source control is to retain stormwater at the source and return to the natural hydrologic cycle through infiltration, evaporation and evapotranspiration. Maintaining the predevelopment flow regimes in urbanised catchments has been recognised as a sensible approach to minimise the impacts associated with hydrologic alterations for preserving the stream channel morphology and the health and integrity of associated aquatic environment (Poff et al., 1997; Prince George's County, 1999; Poff et al., 2010). By retaining stormwater at the source, WSUD helps to attenuate the downstream flooding while returning stormwater into the natural water cycle helps restoring the critical components of natural flow regimes (Poff et al., 1997).

Current stormwater management targets in Australia often endorse preserving channel-forming flows in urbanising catchments at predevelopment level (Victoria Stormwater Committee, 1999; SEQ Healthy Waterways, 2007; Goyder Institute for Water Research, 2011). With the increasing adoption of stormwater source controls for stormwater management in urbanised catchments, they should identify the ability to maintain predevelopment channel-forming flow regimes. The aim of this paper is to assess the performance of infiltration-based WSUD systems in maintaining channel-forming flow regimes in greenfield catchment developments.

\section{CASE STUDY CATCHMENT}

Scott Creek catchment was selected as the case study in this research. Scott Creek is a subcatchment of Onkaparinga catchment located in the Mount Lofty Ranges in South Australia. The catchment spreads over an area of $26.6 \mathrm{~km}^{2}$. The topography of the catchment varies from steep slopes to mildly rolling terrain. The catchment elevation ranges from $503 \mathrm{~m}$ Australian Height Datum (AHD) at Heathfield down to $210 \mathrm{~m}$ AHD at Scott Bottom. The catchment is characterised by a temperate climate with high maximum daily temperatures and evaporation in summer. Rainfall tends to occur during the winter and spring season (May to October) with the majority of the rainfall during the early part of this period, being the winter months. Mean rainfall in the catchment varies from $1100 \mathrm{~mm} / \mathrm{yr}$ at the upper reaches to $800 \mathrm{~mm} / \mathrm{yr}$ at the lower reaches. The 1991-2001 period was selected for catchment modelling; a period during which catchment was at its greenfield conditions.

\section{METHODS}

\subsection{Modelling procedure and catchment scenarios}

Catchment modelling was undertaken to assess the hydrologic performance of WSUD systems in this study. The latest version of the SWMM model (5.0.022) (Rossman, 2010) was selected to perform catchment modelling. This is a widely used modelling tool for catchment land-use change and stormwater control studies and the latest version is equipped with tools to model some of the WSUD devices/systems separately. The case study catchment was modelled using the SWMM model for three catchment land-use scenarios: greenfield catchment condition (natural), urbanised condition without stormwater source controls (urban), and managed catchment condition using WSUD systems (WSUD). Scott Creek was initially modelled using SWMM and then calibrated using PEST automatic calibration software. The calibrated SWMM model was used to simulate both urban and managed catchment scenarios by undertaking necessary data alterations.

The 'urban scenario' represents the catchment development with conventional stormwater drains. The urban scenarios were simulated by changing the directly connected impervious area (DCIA) in the calibrated SWMM model. The catchment was hypothetically modified with $30 \%$ and $70 \%$ DCIA for simulating two different levels of catchment urbanisation scenarios. The 'managed scenario' represents the implementation 
of WSUD systems in a developed catchment to control stormwater. This scenario was modelled by incorporating infiltration-based WSUD systems into the urbanised catchment models. The approach of flow duration control using continuous simulation that has been recommended for designing stormwater control devices for hydromodification control (Geosyntec Consultants, 2008; Palhegyi, 2010a), was adopted in this study. Consequently, sizing of the system was undertaken by matching managed flow duration curves (FDC) to the natural (greenfield) FDC of the catchment.

The selected WSUDs for this study are referred to as 'infiltration-based WSUD systems'. To represent infiltration-based WSUDs in the SWMM model, bio-retention systems were modelled in this scenario. Conceptual diagram of a typical bioretention system is illustrated in Figure 1.

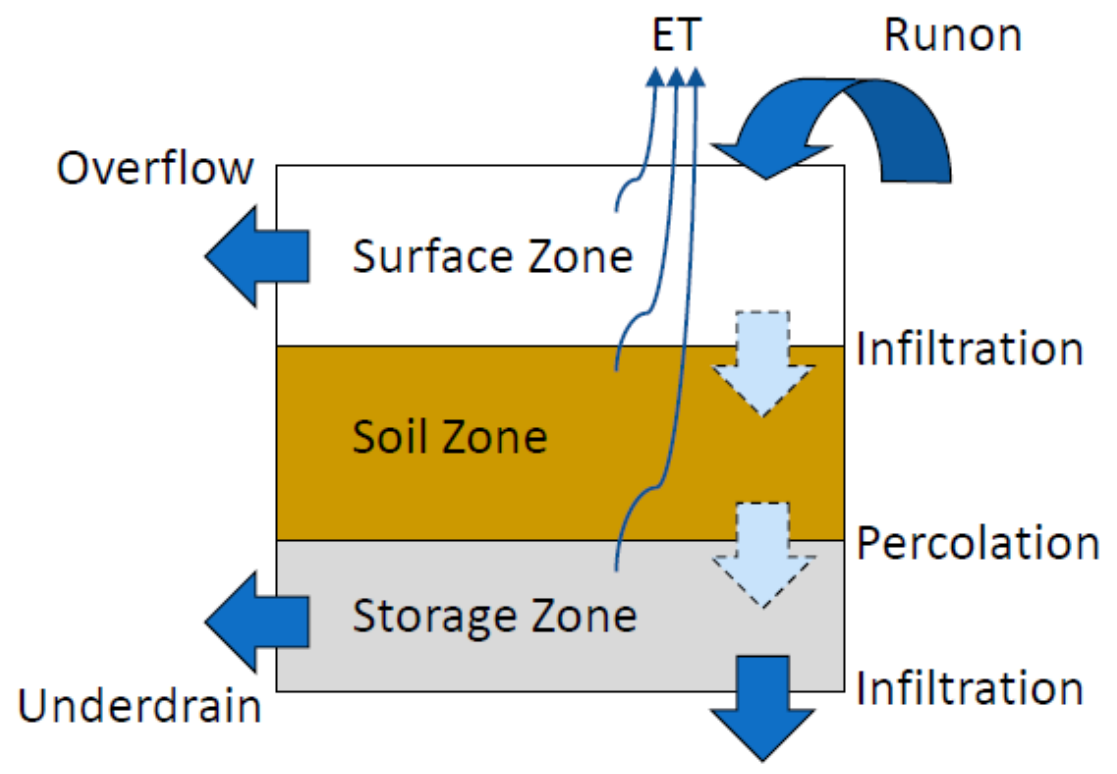

Figure 1: Conceptual diagram of a typical bioretention system (Adopted from Rossman, (2010))

The dimensions of the bioretention systems have to be selected initially for modelling the WSUD systems in SWMM. All the systems were assumed to have similar dimensions, except for the surface area of the systems. System dimensions were initially assigned based on the recommended values in bioretention design manuals and previous studies (Gold Coast City Council, 2007; Palhegyi, 2010b). The design of bioretention facility was undertaken with $350 \mathrm{~mm}$ of surface ponding (surface zone), $600 \mathrm{~mm}$ of amended soil depth (soil zone) and $300 \mathrm{~mm}$ of storage (storage zone). The fraction of area occupied by vegetation above the surface was considered as 0.5 . The amended soil of the bioretention systems was assumed to have the following properties: $50 \%$ porosity, $30 \%$ field capacity, $10 \%$ wilting point and $50 \mathrm{~mm} / \mathrm{hr}$ saturated hydraulic conductivity (Ksat). For the storage layer, porosity of $75 \%$ and initial infiltration rate of $50 \mathrm{~mm} / \mathrm{hr}$ were assigned. Bioretention systems can be designed with and without under drains which are called retention only systems and retention with extended detention systems, respectively. Retention with extended detention systems can be modelled by adding under drains to the retention systems. In this study, bioretention systems were modelled as a mix of both systems.

Sizing of bioretention systems was undertaken as a trial-and-error process by changing the dimensions of the selected WSUD systems until a reasonable FDC match was achieved under maintained conditions to that of the natural conditions. In this approach, the system dimensions and properties noted above were kept constant, except the surface area of the system. The area of the system was altered until a reasonable match between the FDCs of managed condition and the natural (greenfield) condition was achieved. Once an acceptable FDC matching was achieved, the performance of the system was assessed using the selected hydrologic parameters.

\subsection{Evaluating system performance}

The performance of the bioretention systems implemented to control stormwater was assessed in terms of FDCs, flood frequency statistics and flow volume control. The overall systems performance was initially 
assessed by comparison of the FDCs between natural and managed conditions. Flow volume control was assessed by the percentage difference of volume under managed conditions of the catchment with respect to natural flow volume.

The main aim of this paper is to investigate the ability of infiltration-based WSUD systems to replicate predevelopment channel-forming flows in urbanised streams. Hence, the focus of this study is on low return period floods (1.67-year average recurrence interval (ARI)) which are critical for channel stability. Flood quantiles computed using a partial duration series (PDS) are more accurate than those computed using an annual maximum series for ARIs up to 10 years (Institution of Engineers Australia, 1987). Therefore, a PDS was used to determine the magnitude of flood of given return periods. 1.67-year ARI flood in annual maximum series is similar to 1.1-year ARI flood in PDS. The PDS was based on 27 flood peaks extracted from 9 years of flow record, including approximately three flood events in a year for Scott Creek catchment. The analysis was repeated for natural, urbanised and managed scenarios.

\section{RESULTS AND DISCUSSION}

Figure 2(a) and (b) compares the FDCs for natural, urban and managed (WSUD) catchment conditions for $30 \%$ and $70 \%$ DCIA scenarios, respectively.

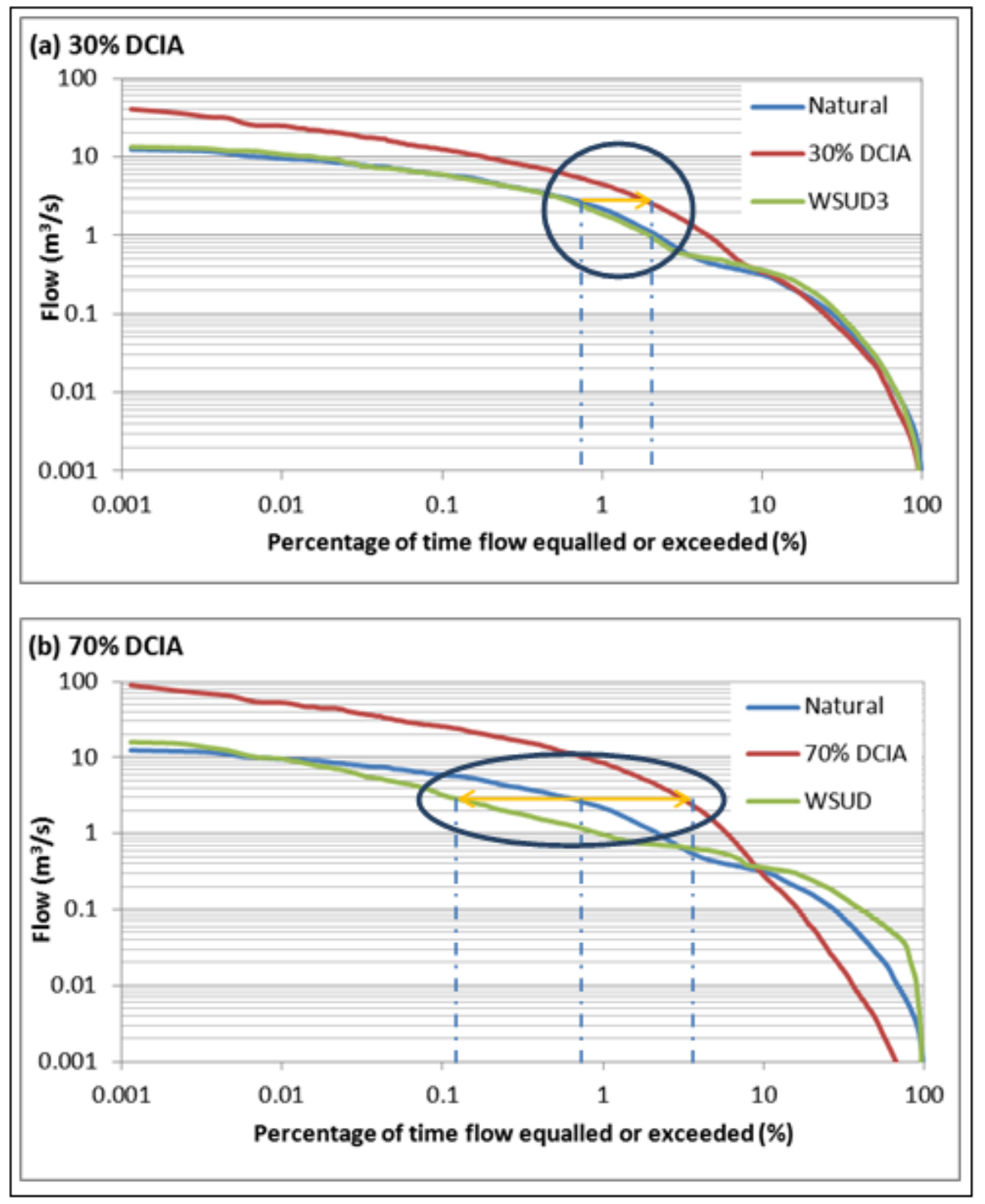

Figure 2: FDCs for natural, urban and managed scenarios of the catchment for $30 \%$ and $70 \%$ DCIA 
As can be seen from Figure 2(a) and (b), greenfield catchment development changes streamflow regimes noticeably and the impact is more severe with increased degree of urbanisation. Peak flows have been increased while low flows have been reduced under urbanised conditions of the catchment and these impacts are more prominent in the $70 \%$ DCIA scenario. The change in channel-forming flow regime with catchment urbanisation is clearly evident through FDC statistics. For instance, the percentage of time that flows exceeded $\mathrm{Q}_{1.67}$ increased from the natural value of $0.71 \%$ to $1.9 \%$ at $30 \%$ DCIA scenario as can be seen from Figure 2(a). Similarly, the percentage of time that flows exceeded $\mathrm{Q}_{1.67}$ increased from the natural value of $0.71 \%$ to $3.3 \%$ at $70 \%$ DCIA scenario. Stormwater management using bioretention systems in developed catchments has effectively reduced the channel-forming flow frequency close to their natural values as can be seen from Figure 2(a) and (b). Under managed scenarios, the percentage of time exceeded of $\mathrm{Q}_{1.67}$ flow has been reduced up to $0.63 \%$ and $0.14 \%$ at $30 \%$ and $70 \%$ DCIA, respectively. Over control of $\mathrm{Q}_{1.67}$ is evident under managed scenario of $70 \%$ DCIA. This can be attributed by over-sizing devices to control extreme peaks rather than frequent flows.

Figure 3 depicts the flood quantiles at selected ARIs for natural, urban (30\% and 70\% DCIA) and managed (30\% and $70 \%$ DCIA) scenarios.

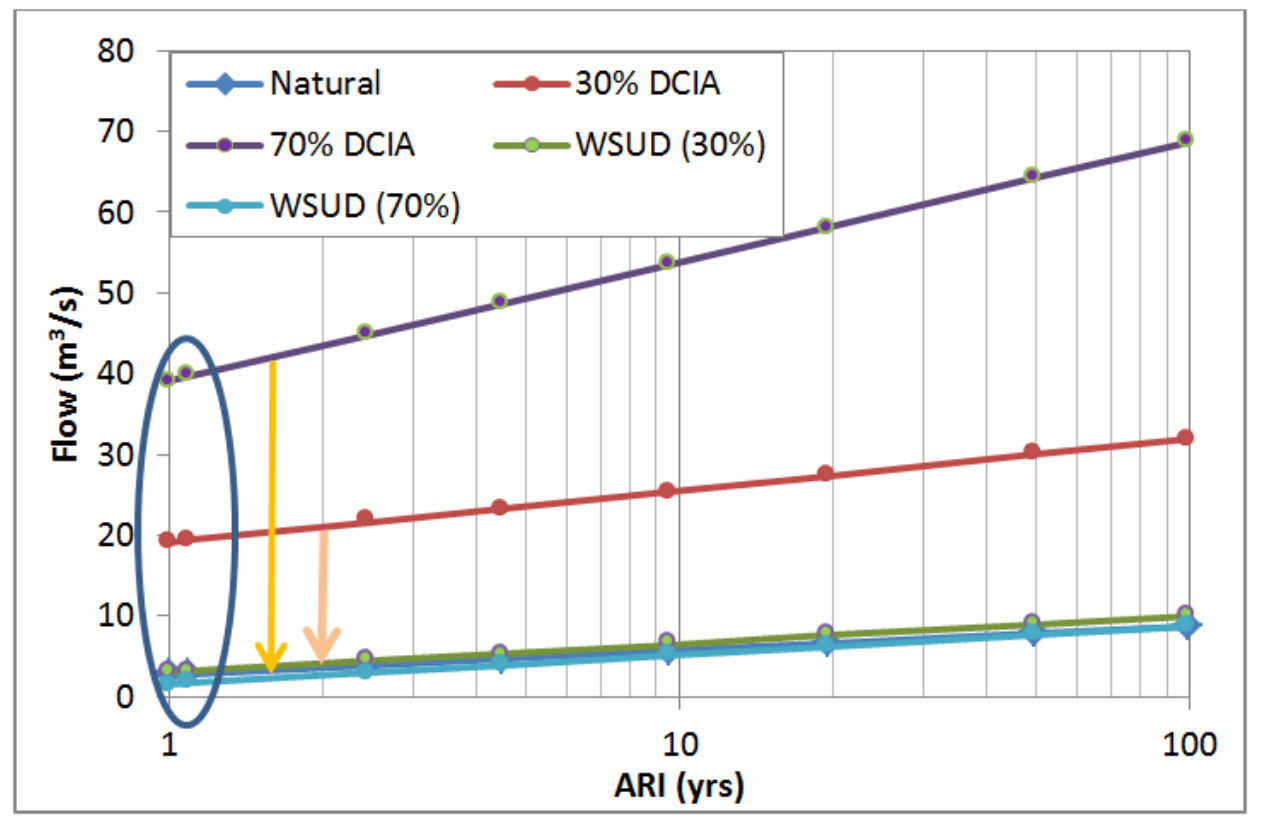

Figure 3: Flood quantiles at selected ARIs for natural, urban (30\% and 70\% DCIA) and managed (30\% and $70 \%$ DCIA) scenarios

The increase of channel forming flow magnitude is evident from Figure 3. Q 1.67 has increased from $2.7 \mathrm{~m}^{3} / \mathrm{s}$ to $19.4 \mathrm{~m}^{3} / \mathrm{s}$ at $30 \%$ DCIA. This is a $586 \%$ of increase from its natural value. Similarly, at $70 \%$ DCIA, the increase in $\mathrm{Q}_{1.67}$ is 14 times that of the natural value (1302\% increase). With the implementation of bioretention systems to manage stormwater in urbanised catchment, $\mathrm{Q}_{1.67}$ has been reduced almost up to the predevelopment level. The difference between the natural and the managed $\mathrm{Q}_{1.67}$ flows is only $13 \%$ and $42 \%$ at 30 and $70 \%$ DCIA scenarios, respectively.

In order to represent the duration parameter, the $\mathrm{D}_{\mathrm{Q} 1.67}$ (Duration of $\mathrm{Q}_{1.67}$ flow) was selected. $\mathrm{D}_{\mathrm{Q} 1.67}$ represents the total hours in flow record that are at or above the $\mathrm{Q}_{1.67}$ value. The duration of $\mathrm{Q}_{1.67}$ flow was increased by $170 \%$ from its natural value at 30\% DCIA scenario while this increase at 70\% DCIA was $360 \%$. After implementing WSUD systems, $\mathrm{D}_{\mathrm{Q} 1.67}$ reduced up to $11 \%$ and $80 \%$ below its natural value at $30 \%$ and $70 \%$ DCIA scenarios.

Flow volume control that can be undertaken by infiltration-based WSUD systems was also assessed. Table 1 list the percentage volume differences under urban and managed conditions of the catchment compared to the natural (greenfield) catchment value.

As seen from Table 1, urbanisation has increased the runoff volume and this increase is severe for increased urbanisation level. The ability of infiltration-based

Table 1. Percentage difference of flow volume for urban and managed scenarios compared to natural scenario

\begin{tabular}{|l|c|c|}
\hline \multicolumn{1}{|c|}{ Scenario } & 30\% DCIA & 70\% DCIA \\
\hline Urban & $64 \%$ & $153 \%$ \\
\hline Managed & $6 \%$ & $13 \%$ \\
\hline
\end{tabular}


systems to manage runoff volume is evident from managed catchment scenarios. Adopted WSUD systems have reduced the dramatically increased flow volume close to natural values. Infiltration-based systems promote runoff reduction through infiltrating and evaporating captured overland flow. Hence, these WSUD systems are effective in attenuating notably increased flow volume under urbanised conditions of the catchment.

One of the major assumptions used when modelling WSUD systems for the selected catchments was that the site conditions were completely appropriate for infiltration-based stormwater controls. Generally, infiltrationbased WSUD systems require deep infiltrative geologic strata at or near the ground surface to accommodate the large volumes of runoff collected (Konrad and Booth, 2005). In some catchments, geologic conditions appropriate for infiltration-based WSUD are limited or absent, therefore, it is highly unlikely that the use of infiltration-based WSUD systems would be applied to an entire catchment or region for stormwater control. Where these limitations exist, non-leaky devices or aquifer storage can be used instead. In reality, the Scott Creek catchment comprises fractured rock aquifers which are unsuitable for infiltration-based stormwater controls. However, the selection of this catchment for this study was due to the availability of catchment information and hydrometeorological data for catchment modelling. Also it should be noted that the implications of infiltration on salinity issues and groundwater quality have not been considered in this hydrologic evaluation.

\section{CONCLUSIONS}

Although source control techniques are increasingly being adopted to manage stormwater in urbanising catchments, their ability to manage flow regimes is yet to be investigated. This paper assessed the ability of the infiltration-based WSUD systems to replicate predevelopment channel-forming flow regimes in a greenfield catchment development. The system was modelled by simulating three catchment scenarios: natural (greenfield), urban and managed conditions. Continuous simulation of flows was adopted to design the WSUD systems. Magnitude, frequency and duration statistics of channel-forming flow were dramatically changed following catchment urbanisation. The results of the study depicts that the adopted infiltration-based WSUD systems can manage the channel-forming flow magnitude, frequency and duration close to their predevelopment level while maintaining flow volumes close to natural values. The percentage of time that flows exceeded $\mathrm{Q}_{1.67}$ increased significantly with catchment urbanisation. Employing bioretention systems to control stormwater effectively reduced the channel-forming flow frequency close to their natural values, bringing flow frequency of $\mathrm{Q}_{1.67}$ back to $0.63 \%$ and $0.14 \%$ at $30 \%$ and $70 \%$ DCIA scenarios. The dramatically increased channel-forming flow magnitude followed by urbanisation reduced close to predevelopment values and difference between the natural and the managed $\mathrm{Q}_{1.67}$ flows being only $13 \%$ and $42 \%$ at $30 \%$ and $70 \%$ DCIA scenarios, respectively. Infiltration-based WSUD systems reduced the increased channel-forming flow durations up to $11 \%$ and $80 \%$ below the natural values. These results emphasise that WSUD systems would help to reduce the impact of urbanisation on channel geometry and ecological health.

\section{REFERENCES}

Bledsoe, B.P., and C. Watson (2001). Effects of urbanisation on channel instability, Journal of the American Water Resources Association, 37 (2), pp. 255-270.

Booth, D.B. (1991). Urbanization and the natural drainage system-impacts, solutions, and prognoses, The Northwest Environmental Journal, 7(1), pp. 93-118.

Geosyntec Consultants (2008). Evaluation of post-construction hydromodification requirements contained in the preliminary draft general construction permit, Geosyntec Consultants, Los Angeles, California.

Gold Coast City Council (2007), Policy 11: Land development guidelines, Section 13.4 Bioretention swales, Goldcoast Planning Scheme Policies, Gold Coast City Council, Gold Coast, Queensland.

Goyder Institute for Water Research (2011). Interim Water Sensitive Urban Design targets for Greater Adelaide, Technical Report Series No. 11/7, Goyder Institute for Water Research, Adelaide, South Australia.

Institution of Engineers Australia (1987). Australian rainfall and runoff, The Institution of Engineers, Australia, Barton, ACT.

Konrad, C.P. and D.B. Booth (2005). Hydrologic changes in urban streams and their ecological significance, Paper presented at the American Fisheries Society Symposium, Bethesda, MD, pp. 157-177. 
Palhegyi, G.E. (2010)a. Developing solutions for urban stormwater management to promote sustainable ecosystems: Science and application, Journal of Hydrological Engineering, 15(6), pp. 504-511.

Palhegyi, G.E. (2010)b. Modelling and sizing bioretention using flow duration control, Journal of Hydrologic Engineering, 15(6), pp. 417-425.

Paul, M.J., and J.L. Meyer (2001). Streams in urban landscapes, Annual Review of Ecology and Systematics, 32(1), pp. 333-365.

Poff, N.L., Allan, J.D., Bain, M.B., Karr, J.R., Prestegaard, K.L., Richter, B.D., Sparks, R.E., and J.C. Stromberg (1997). The natural flow regime, BioScience, 47(11), pp. 769-784.

Poff, N.L., Richter, B.D., Arthington, A.H., Bunn, S.E., Naiman, R.J., Kendy, E., Acreman, M., Apse, C., Bledsoe, B.P., Freeman, M.C., Henriksen, J., Jacobson, R.B., Kennen, J.G., Merritt, D.M., O’Keeffe, J.H., Olden, J.D., Rogers, K., Tharme, R.E. and A. Warner (2010). The ecological limits of hydrologic alteration (ELOHA): a new framework for developing regional environmental flow standards, Freshwater Biology, 55(1), pp. 147-170.

Prince George's County (1999), Low impact development design strategies: An integrated design approach, Department of Environmental Resources Programs and Planning Division, Prince George's County, Largo, Maryland.

Rossman, L.A. (2010). Storm Water Management Model User's Manual; Version 5.0, U.S. Environmental Protection Agency, Cincinnati, $\mathrm{OH}$.

SEQ Healthy Waterways (2007), Water Sensitive Urban Design: Developing design objectives for urban development in South East Queensland-Version 2, South East Queensland Healthy Waterways Partnership, Brisbane, Queensland.

Victoria Stormwater Committee (1999), Urban stormwater: Best practice environmental management guidelines, CSIRO Publishing, Melbourne, Australia. 